Revista de la red interuniversitaria de estudios sobre las literaturas rioplatenses contemporáneas en Francia

21 | 2020

Glosolalias transplatinas: fantasmas, utopías y

ficciones lingüísticas

\title{
Las novelas argentinas del siglo 21
}

Les romans argentins du XXIe siècle

The 21st Century Argentine Novels

\section{Soledad Sánchez Flores}

\section{OpenEdition}

\section{Journals}

Edición electrónica

URL: http://journals.openedition.org/lirico/9607

DOI: $10.4000 /$ lirico. 9607

ISSN: 2262-8339

Editor

Réseau interuniversitaire d'étude des littératures contemporaines du Río de la Plata

Referencia electrónica

Soledad Sánchez Flores, «Las novelas argentinas del siglo 21», Cuadernos LIRICO [En línea], 21 | 2020,

Publicado el 12 julio 2020, consultado el 29 enero 2021. URL: http://journals.openedition.org/lirico/ 9607 ; DOl: https://doi.org/10.4000/lirico.9607

Este documento fue generado automáticamente el 29 enero 2021.

\section{c) (i) $\Theta$}

Cuadernos LIRICO está distribuido bajo una Licencia Creative Commons Atribución-NoComercialSinDerivar 4.0 Internacional. 


\title{
Las novelas argentinas del siglo 21
}

\author{
Les romans argentins du XXIe siècle \\ The 21st Century Argentine Novels
}

Soledad Sánchez Flores

\section{REFERENCIA}

Gallego Cuiñas Ana, Las novelas argentinas del siglo 21: nuevos modos de producción, circulación y recepción, Nueva York, Peter Lang, 2019, 160 páginas.

Más que un mapa exhaustivo de la literatura argentina del siglo 21 cuya extensión resultaría inabarcable, Gallego Cuiñas se propone trazar "una suerte de escaparate metafórico" (xi) estructurado en cuatro capítulos cuyos ejes reflexivos se gestan en un qué, un cómo y un dónde. Estos interrogantes sirven como estrategia para revelar algunas de las conclusiones que la autora ha venido desarrollando a lo largo de su carrera investigadora y de su labor docente dentro de la Universidad de Granada. El ensayo parte del reconocimiento de una parcialidad crítica determinada, como la autora misma reconoce, por el lugar de enunciación que ocupa como argentinista española, que se manifiesta en una voz propia y mediante un estilo expositivo que se fundamenta en la formulación de preguntas más que en sentencias conclusivas. Pone de esta forma en práctica el método de las "preguntas-caracol" de la parábola de Shunruy Suzuky, para el que una pregunta bien formulada lleva en sus espaldas su propia respuesta. La autora parte de la consideración de que lo nuevo no son las estéticas ni los temas sino las condiciones materiales, una premisa que revela desde el principio la línea materialista que guiará toda la investigación, sin soslayar por ello el análisis estético del corpus textual elegido. Este corpus se centra en primeras novelas de autores argentinos publicados en el nuevo siglo, una selección que obedece a la hipótesis de que es en la opera prima donde mejor se evidencia la posición del escritor con respecto a su tradición literaria nacional. Desde esa doble mirada, intra y extratextual, Gallego Cuiñas presenta las claves más significativas del estado actual de la novela argentina. 
2 La autora coloca la cuestión del valor literario como eje transversal y parte de la consideración de una crisis ontológica literaria que afecta de lleno a la novela del siglo 21: ya no se define por categorías absolutas como las de obra, autor o campo, sino que la desterritorialización que se produce a partir de los años ochenta ha dado lugar a la inutilidad de dichas nociones, que devienen una suerte de categorías zombies. Una de las consecuencias más evidentes es la profesionalización del oficio de escritor, ahora espectacularizado por el mercado, que se convierte en un producto de consumo en muchas ocasiones tan importante como su propia obra. Esto se percibe en el acercamiento entre literatura y vida, que tiene consecuencias, entre otros factores, en el protagonismo de la narrativa autoficcional o en la valoración literaria del autor más allá de su propia obra textual. A este respecto es destacable el análisis que realiza en el capítulo segundo para el caso de la autora Pola Oloixarac, mediante una reflexión materialista de la producción y circulación de su primera novela publicada en España, Las teorías salvajes, en cuya recepción se observa una mediatización de la autora a través de su imagen sexualizada y de sus declaraciones sobre los aspectos más banales de la novela (por ejemplo, la elección del color rosa de la portada inspirado en su bikini favorito).

3 De este modo, nos acercamos a otra de las claves hacia las que apunta Gallego Cuiñas, la visibilidad como uno de los principales instrumentos de tasación económica y simbólica. Esta visibilidad se gesta en la acción de una serie de dispositivos que tienen un papel protagonista en el escenario literario internacional, los llamados gatekeepers: tomando como base teórica a Thompson, la autora muestra cómo estos dispositivos ejercen de mediadores mundiales y creadores de gusto literario, es decir, consagradores de la nueva literatura mundial. Los eventos literarios como la Feria del Libro de Frankfurt, las listas de autores como las de Granta o Bogotá39, agentes y talleres literarios, becas, residencias, traductores y editoriales, legitiman y visibilizan a los autores y sus nuevas literaturas latinoamericanas, entre ellas la argentina. La propuesta teórica que la autora presenta sobre la relevancia de estos gatekeepers en el nuevo siglo se fundamenta en el análisis concreto de ciertos casos; por ejemplo, dedica una especial atención al antes y el después que constituyen listas como las de Granta o Bogotá39 en el proceso de circulación internacional de los nuevos autores argentinos: sirven como lanzadores internacionales de autores locales y de legitimadores de aquellos que, como Schweblin, ya han sido publicados por editoriales de otros países europeos. Otras características que tienen en común los autores argentinos de estas listas es que la mayoría son representados por agentes literarios europeos (en Granta todos los autores vienen de agentes catalanes menos Puenzo y Pron, con agencias alemana e inglesa respectivamente) y, además, casi todos ellos vienen de una formación en diferentes talleres literarios: por ejemplo, Almada en el de Alberto Laiseca, Enríquez en el de Tomás Eloy Martínez y Schweblin en el de Liliana Heker.

El análisis que Gallego Cuiñas hace sobre los talleres literarios constituye una reflexión novedosa en el espacio de la crítica española. Se trata de un dispositivo literario que, como apunta la autora, tiene un arraigo destacable en ámbito latinoamericano que no se percibe con la misma impronta en el caso de España. Deudores de los programas de escritura creativa anglosajones, estos talleres experimentan una gran crecida a mediados del siglo pasado con la irrupción del Boom latinoamericano y viven en estas últimas décadas un protagonismo sin precedentes, que va de la mano de la proliferación de títulos universitarios de grado y posgrado conducentes a la 
profesionalización del escritor: "el taller literario es a la editorial independiente como el máster de escritura creativa al gran conglomerado" (82). Gallego Cuiñas da cuenta de la especial importancia que estos talleres cobran en el espacio argentino, y observa cómo la mayor parte de los escritores argentinos que circulan y se traducen a nivel transnacional alguna vez han pasado por alguno de estos talleres. Estos no solo actúan desde un costado económico (nuevos profesionales talleristas o acceso a la publicación), sino también a nivel simbólico, en tanto gestan una suerte de linaje donde el maestro tallerista sirve como marca de reconocimiento del autor que acaba de publicar, esto es, el maestro tallerista como agente literario y gatekeeper de los autores a los que forma: no solo los reseña en la contraportada de sus primeras publicaciones, sino que les presta su red de contactos (traductores, editores, premio, etc.).

5 Las reflexiones que realiza sobre el mercado editorial constituyen otro de los grandes pilares de este ensayo, tanto que la autora propone sustituir para el espacio global la categoría de "campo" ideada por Bourdieu (que quedaría restringida tan solo a ciertos espacios nacionales o locales) por la categoría de "mercado": "es el mercado el que evalúa, fija posiciones y otorga valor, desde cada uno de sus mediadores, en el comercio literario mundial" (5). En lo que respecta las editoriales comerciales e independientes (una denominación que la autora reconoce compleja), apunta hacia una novedad fundamental para entender la novela argentina del siglo 21: el proceso de balcanización del sector editorial como efecto de la irrupción de las editoriales independientes, que afecta de lleno al protagonismo de nuevas manifestaciones literarias hasta el momento minoritarias, como la literatura de mujeres y una estética localista cuya marca más evidente es la lengua, ya sea mediante la representación de un español no neutralizado (frente a la tradicional estandarización por la que las editoriales españolas habían apostado hasta el momento) o por la ilegibilidad como posición de resistencia al consumo de masas. Además, el protagonismo de las independientes en la formación de la nueva literatura latinoamericana se demuestra a través de nuevos "pactos" de mediación: el catálogo de muchas independientes locales que no tienen alcance internacional funciona como filtro para editoriales de mayor envergadura, que han sabido ver en estas editoriales locales un manantial de nueva literatura, un manantial que fagocitan al tiempo que se erigen como "descubridoras". Este descubrimiento no deja de ser una verdad a medias ya que, como apunta Gallego Cuiñas, hasta el momento se ha perpetuado un "centralismo esteticista" enunciado desde la alta cultura y desde centros hegemónicos de poder como París, Barcelona o Nueva York, de modo que el horizonte ideológico y estético es construido solo sobre aquello que circula-leemos/ vemos- en dichos espacios. La autora lo argumenta en el capítulo tres con el caso de Mansalva, Mardulce o Eterna Cadencia, tres editoriales independientes con una marca a la vez estética y política que las define: "la desmetaforización que defiende Mansalva, la ilegibilidad de Mardulce, la vanguardia de Eterna Cadencia" (71). Grandes grupos internacionales como Random House, Planeta o Anagrama fijan la atención sobre aquellos autores que reciben una buena acogida por parte de la crítica académica local, de premios literarios o del propio público subalterno. Gallego Cuiñas lo ejemplifica también con los casos de Selva Amada, Pola Oloixarac y Samanta Schweblin, que solo han publicado en Random House después de haber pasado por la edición de editoriales independientes locales, o por otros gatekeepers que los han legitimado: por medio de Granta (Pola Oloixarac), de académicos de influencia en el espacio internacional como Beatriz Sarlo (Selva Amada), o por un premio literario como el Premio Nacional de las Artes en Argentina (Samanta Schweblin). No obstante, Gallego Cuiñas observa cómo 
esta circunstancia genera a su vez reacciones adversas que se resisten a la hegemonía de estos grandes conglomerados. Así, ciertos autores optan por publicar tan solo en sellos independientes (Romina Paula o Murphy por ejemplo) mientras que otros actúan de forma bicéfala, alternando la publicación en comerciales como manera de ganar visibilidad y en independientes como lealtad literaria. Otra forma de resistencia destacable sería la de la editorial Eterna Cadencia, en cuyo caso la autora se detiene con especial atención: su protagonismo en estos últimos años le ha disputado el puesto como primer gatekeeper de literatura latinoamericana a la editorial Anagrama, que si bien no deja de tener influencia, asienta su catálogo sobre el filtro de otras editoriales independientes latinoamericanas a la vez que (re)produce unos valores hegemónicos europeos; Eterna Cadencia propone una política muy diferente basada en la disrupción, esto es, en la publicación de nuevos valores de lo latinoamericano.

6 De este modo, literaturas de carácter local penetran en un espacio hegemónico afectando directamente en la creación del gusto literario y en "la (pre)figuración de un futuro canon latinoamericano" (110). Así, el catálogo de estos grandes conglomerados abre un espacio para consumidores específicos al ofrecer nuevas estéticas subalternas que se manifiestan ya no solo en una experimentación estética basada en la ilegibilidad o la desmetaforización (al modo de editoriales como Mardulce o Mansalva) sino también en el carácter localista de la propia temática y en el protagonismo de la narrativa escrita por mujeres. Gallego Cuiñas acude en el capítulo cuatro a una serie de escritoras sobre las que analiza ciertos rasgos estéticos de sus primeras novelas para descubrir de qué forma manifiestan la problemática de lo femenino: Selva Amada, Mariana Enríquez y Samanta Schweblin. La literatura de estas escritoras no pretende apropiarse de grandes temas de Historia, Política y Filosofía asociados a la literatura masculina (como ocurría con Rosario Castellanos o Elena Poniatowska) y tampoco buscan simplemente dar visibilidad a una voz propia de mujeres (como en el caso de Isabel Allende, Laura Esquivel o Ángeles Mastretta); la novedad radica en el alejamiento tanto de una ideología patriarcal como del encasillamiento de una literatura "femenina" mediante diferentes estrategias que ponen en jaque "a la institución del matrimonio, los roles de esposa y madre, la familia y la misma identidad -en devenir y performática- de la mujer mundial (no específicamente latinoamericana)" (116). Por otro lado, el localismo temático viene del diálogo con su pasado histórico más reciente, y de la resemantización de la dicotomía rural/urbano. El primer caso, las llamadas por Drucaroff novelas de "posdictadura", lo argumenta a partir de los análisis de las primeras novelas de Felix Bruzzone y de Florencia Abbate, donde la denuncia se mezcla con "el absurdo, el desarraigo y la impostura" (41). El segundo caso lo expone a través de novelas como las de Gabriela Cabezón Cámara, Iosi Havilio o Roque Larraquy, donde se disuelve la noción de frontera y la barbarie ya no se opone a la civilización, sino que se funden; el espacio no viene determinado por el lugar de enunciación sino por las relaciones sociales que se gestan entre los personajes.

7 Asimismo, la violencia se torna un elemento predominante en todas estas novelas, manifestada a través del cuerpo como cosificación: la carne como prueba incontestable frente a la liquidez de la sociedad neoliberal del nuevo siglo.

8 En definitiva, este ensayo de Ana Gallego Cuiñas se inserta dentro del debate sobre el estado actual de la literatura (novela) latinoamericana (argentina), mediante una voz propia que revela algunas de las claves fundamentales para entender cómo funciona una literatura local dentro de un contexto global, donde la novedad no viene de las 
estéticas y los temas sino del lugar desde donde se enuncian y se leen estas nuevas literaturas: "no se puede equiparar al lector porteño que compra en Buenos Aires 'literatura argentina' al lector español que compra en Barcelona 'literatura argentina" (8). Partiendo de un análisis que va de la reflexión teórica a su demostración práctica mediante el estudio de casos intra y extratextuales, demuestra cómo la unión entre sociología y crítica literaria no solo es posible sino necesaria para cartografiar la literatura del nuevo siglo: el qué, el cómo y el dónde de la novela argentina se funden en la transversalidad del mercado y de los gatekeepers como dispositivos que constituyen la gran novedad literaria del siglo 21 .

\section{AUTORES}

\section{SOLEDAD SÁNCHEZ FLORES}

Universidad de Granada

Solesf@ugr.es 